\title{
Infrared Spectroscopy and Thermal Stability Studies of Natural Rubber-Barium Ferrite Composites
}

\author{
Khaled H. Mahmoud ${ }^{1 *}$, Mahmoud H. Makled $^{2}$ \\ ${ }^{1}$ Physics Department, Faculty of Science, Taif University, Taif, KSA \\ ${ }^{2}$ Physics Department, Faculty of Science, Benha University, Benha, Egypt \\ Email: cairouni1@yahoo.com
}

Received December 13, 2011; revised January 15, 2012; accepted January 26, 2012

\begin{abstract}
Natural Rubber (NR)-barium ferrite (BaF) composites (RFCs) have been prepared. Structural features of the composites were characterized by Infrared spectroscopy and scanning electron microscope (SEM). Differential scanning calorimetry (DSC) analysis showed that there is small variation of glass transition temperature $\left(\approx-1^{\circ} \mathrm{C}\right)$. The activation energy of glass transition was calculated by Kissinger method and has values between $(53-110 \mathrm{~kJ} / \mathrm{mol})$. Thermodynamic parameters such as activated entropy, enthalpy and Gibbs free energy were calculated for glass transition also. Thermogravimetric analysis TG and its derivative DTG showed one stage thermal decomposition between $300^{\circ} \mathrm{C}-400^{\circ} \mathrm{C}$ with weight loss between $(19.47 \%-52.13 \%)$. Increasing barium ferrite loading will increase the thermal stability of natural rubber. The kinetic parameters such as activation energy, entropy, enthalpy and Gibbs free energy for composites in the decomposition region were calculated and analyzed using Coats-Redfern technique.
\end{abstract}

Keywords: Natural Rubber; Barium Ferrite; TG; Thermal Stability

\section{Introduction}

Natural Rubber (NR) has long been considered as an excellent general purpose polymer with wide-ranging industrial applications. Also, its unique combination of properties has made it an elastomer of choice for many of the sophisticated engineering applications [1]. However, one of the limitations of NR is its low value of hightemperature stability. Quite often, the additives, such as plasticizers, fillers, curatives, flame-retardants, etc., used for compounding, affect the thermal and thermo-oxidative stability of the base polymer, good information about which may be obtained from thermal analysis methods such as TGA, DSC. Hard ferrite or ceramic permanent magnets are considered to be an important and sophisticated class of engineering materials, which are used extensively in various applications. Hexaferrite magnets have found acceptance in many electronic products, as a result of their superior cost efficiency, large corecivity, and specific magnetic saturation associated with their high magnetic and chemical stability [2,3]. The advantages of polymer bonded magnets over their metallic and ceramic counterparts include low weight and cost, resistance to corrosion, ease of machining and forming, and capability of high production [4]. The impregnation of magnetic fillers in the matrix imparts magnetic properties

"Corresponding author. and modifies the physical properties of the matrix considerably [5]. A few researches have reported the processing and dynamical properties of polymer composites containing hexaferrite prepared by ordinary methods up to $120 \mathrm{phr}$ (part per hundred part of rubber). The result indicates poor adhesion between ferrite particles and polymer, in spite of the fact that the percolation was not achieved yet for these types of composites. The maximum loading was about $120 \mathrm{phr}$ [6-9].

This work forms part of a comprehensive study focusing on the fabrication of hard magnetic ferrite and rubber-ferrite composites (RFCs), and study their physical properties (curing, mechanical, magnetic, and electrical properties) as a function of ferrite content. The present manuscript is an attempt to understand the IR, thermal stability and decompositions characteristic in the case of high coercivity materials-polymer composites as a function of ferrite loading up to $200 \mathrm{phr}$.

\section{Experimental Procedure}

Barium ferrite powders having a coercive force of $5.2 \mathrm{kOe}$, magnetization $67 \mathrm{emu} / \mathrm{gm}$ and $45-200 \mu \mathrm{m}$ particle size were prepared by a coprecipitation method according to Makled et al. [10]. After characterization they were mixed with a natural rubber ADS (air dried sheet) by various loading up to $200 \mathrm{phr}$ to form rubber-ferrite 
composites (RFCs). The recipe used for this study is given in Table 1. The composites were prepared in a two-roll mixing mill and after homogenization they were cured and molded into thin sheets of $1-2.5 \mathrm{~mm}$ in thickness at $150^{\circ} \mathrm{C}$ using a hydraulic press according to ASTM D-15. The SEM samples were prepared by fracturing the samples and polishing the surfaces under liquid nitrogen, followed by carbon coating. The IR analysis was performed using a PYE spectrophotometer over the range $200-1000 \mathrm{~cm}^{-1}$. Thermal analysis was carried out using a computerized DSC and TGA, TA-50 Schimadzu Corporation, Kyoto, Japan. Measurements were carried under nitrogen atmosphere $(30 \mathrm{ml} / \mathrm{min})$.

\section{Results and Discussion}

\subsection{SEM Characterization}

Figure 1 shows the distribution of ferrite particles in rubber matrix at $200 \mathrm{phr}$. The variation of particle sizes, the broad particle distribution, and the homogeneous

Table 1. Formulation of the mixes for preparing natural rubber-barium ferrite-composites.

\begin{tabular}{lc}
\hline \multicolumn{1}{c}{ Ingredient } & Phr (part per hundred rubber) \\
\hline Rubber (ADSI-XI) & 100 \\
Steric acid & 1 \\
Zinc oxide & 5 \\
Accelerators (CBS) & 0.6 \\
Antioxidant (AW) & 1 \\
Sulfur & 1.5 \\
Ferrite & $30,90,140,160,180,200$ \\
\hline
\end{tabular}

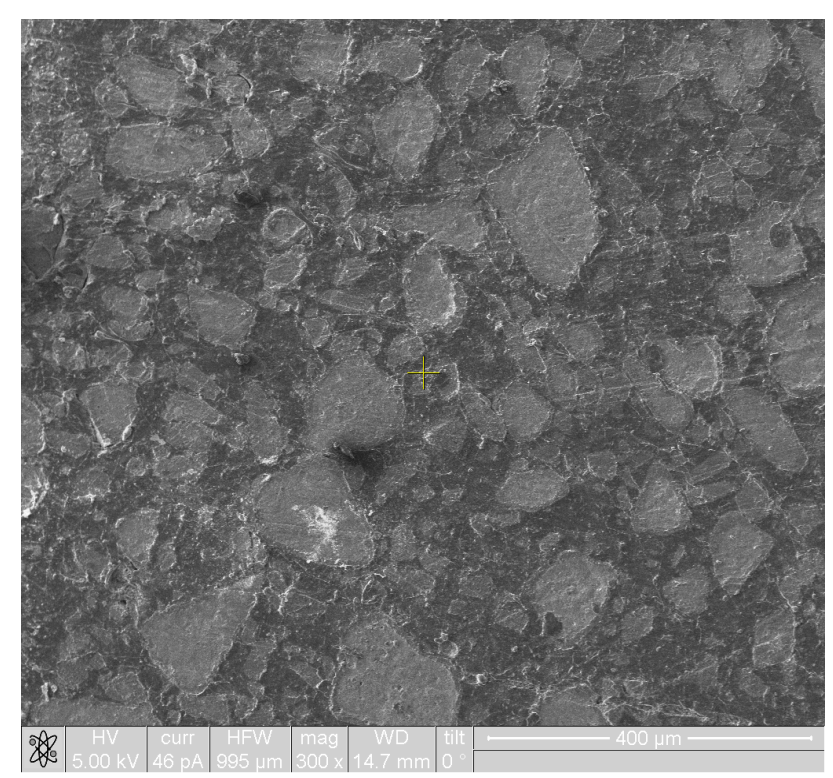

Figure 1. SEM image for natural rubber-barium ferrite composites at 200 phr ferrite loadin. dispersion can be observed. It also noticed there is no tendency to form agglomerates in the present RFCs even at high loading level. These unusual behaviors can be attributed to the nature of ferrite particles and the degree of mixing, which are critical factors in controlling the physical properties of a polymer-bonded magnet [11].

\subsection{IR Spectroscopy}

Infrared studies indicated the presence of two strong absorption bands $v_{1}$ and $v_{2}$ which are found in the expected range as shown in Figure 2. Assignment of bands is given in Table 2 . The high frequency band $v_{1}$ is in the range 590 to $600 \mathrm{~cm}^{-1}$ and the lower one $v_{2}$ in the rang 438 to $446 \mathrm{~cm}^{-1}$. The change in the band position is due to the change in the $\mathrm{Fe}^{3+}-\mathrm{O}^{2-}$ internuclear distance of the octahedral and tetrahedral sites. Waldron [12] and Hafner [13] attributed the $v_{1}$ to the intrinsic vibration of the tetrahedral groups, whereas $v_{2}$ is due to is due to octahedral groups. A small band $v_{3}$ in the range of 334 to $342 \mathrm{~cm}^{-1}$ is assigned to the divalent octahedral metal ions - oxygen ion complex [14]. The appearance of the band $v_{4}$ in the range $292-298 \mathrm{~cm}^{-1}$ depends on the mass of the divalent tetrahedral cation and is assigned to the lattice vibration [15]. It is also observed that, $v_{1}$ shifts towards higher frequency side with increasing particle size. The reason for this could be attributed to shifting of $\mathrm{Fe}^{3+}$ ions toward oxygen ions with increasing the particle size, then the average bond length increases.

\subsection{Differential Scanning Calorimetry and Thermodynamic Parameters}

DSC provides information concerning the enthalpy change accompanying a physical or chemical event, within a material. The glass transition is a second order event, which manifests itself in a DSC curve as a step changing corresponding to the change in the heat capacity of the system [16].

Figure 3 shows DSC curves measured from natural rubber-barium ferrite composites at heating rate $10^{\circ} \mathrm{C} / \mathrm{min}$. The curves exhibited changes in the base line in the temperature range $\left(-59^{\circ} \mathrm{C}-58^{\circ} \mathrm{C}\right)$ which are attributed to the

Table 2. IR absorptions bands for natural rubber-barium ferrite-composites.

\begin{tabular}{ccccc}
\hline Particle size $/ \mu \mathrm{m}$ & $v_{1}$ & $v_{2}$ & $v_{3}$ & $v_{4}$ \\
\hline Normal & 594 & 444 & 340 & 292 \\
Less 45 & 596 & 438 & 335 & - \\
$45-75$ & 596 & 442 & 334 & 294 \\
$75-100$ & 600 & 446 & 342 & 298 \\
$100-200$ & 600 & 440 & 336 & 293 \\
Up 200 & 590 & 444 & 338 & 296 \\
\hline
\end{tabular}




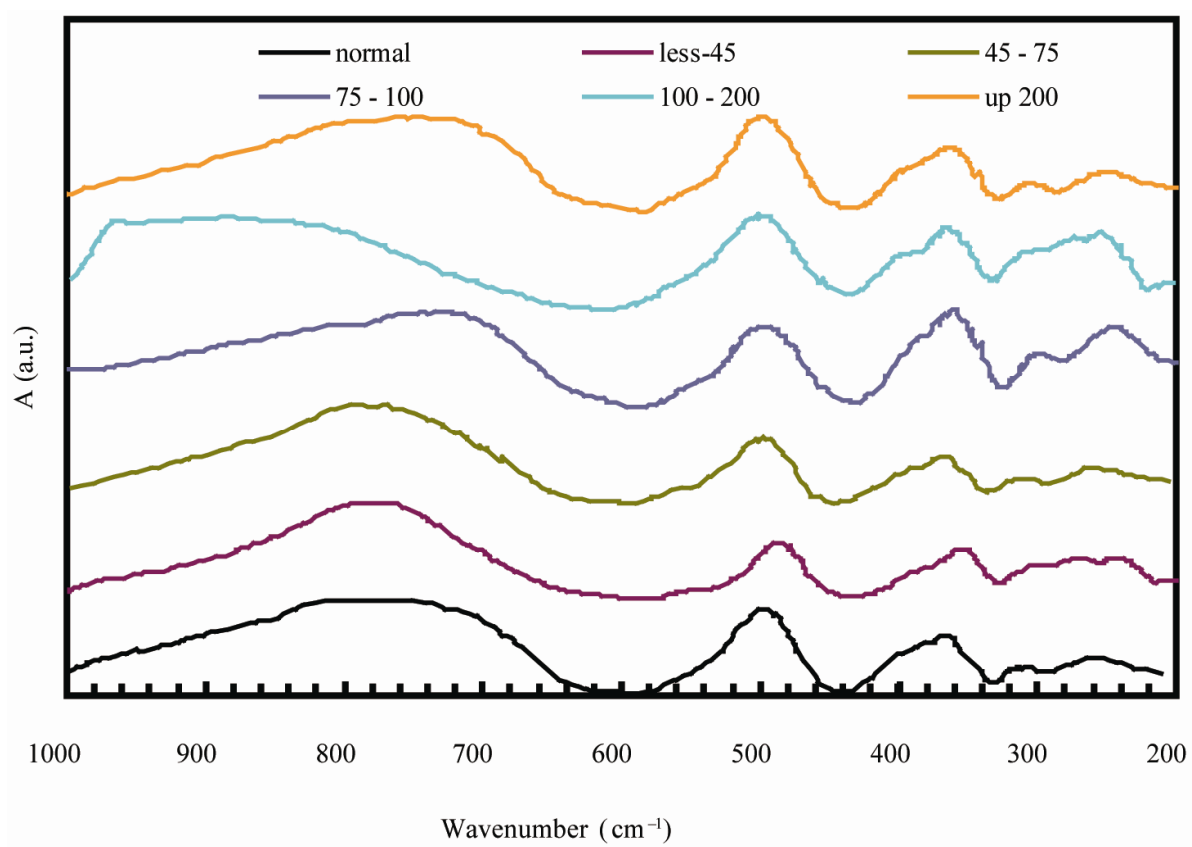

Figure 2. IR spectra of for natural rubber-barium ferrite composites.



Figure 3. DSC thermograms for natural rubber-barium ferrite composites.

glass transition temperatures of the investigated samples. The results of the glass transition temperatures are sum- marized in Table 3 . The variation of glass transition temperature with ferrite loading is small $\left(\approx-1^{\circ} \mathrm{C}\right)$. This 
Table 3. Glass transition thermodynamic parameters for natural rubber-barium ferrite composites.

\begin{tabular}{ccccccc}
\hline Barium ferrite loading $(\mathrm{Phr})$ & $T_{g}\left({ }^{\circ} \mathrm{C}\right)$ & $A\left(S^{-1}\right)$ & $E_{a}(\mathrm{~kJ} / \mathrm{mol})$ & $\Delta S^{\#}(\mathrm{~J} / \mathrm{mol} \cdot \mathrm{K})$ & $\Delta H^{\#}(\mathrm{~kJ} / \mathrm{mol})$ & $\Delta G^{\#}(\mathrm{~kJ} / \mathrm{mol})$ \\
\hline 0 & -59 & $2.61 \times 10^{15}$ & 69 & 52.97 & 67.22 & 55.88 \\
30 & -58 & $1.04 \times 10^{13}$ & 53 & 6.998 & 51.21 & 49.71 \\
90 & -59 & $2.29 \times 10^{19}$ & 85 & 128.461 & 83.22 & 55.73 \\
140 & -59 & $2.6 \times 10^{23}$ & 101 & 206.09 & 99.22 & 55.12 \\
160 & -58 & $2.54 \times 10^{25}$ & 110 & 244.15 & 108.21 & 55.72 \\
180 & -59 & $1.3 \times 10^{17}$ & 76 & 85.46 & 74.22 & 55.93 \\
200 & -58 & $1.57 \times 10^{20}$ & 81 & 144.42 & 79.21 & 48.16 \\
\hline
\end{tabular}

small variation could be associated with the imposed restriction due to the interaction between the filler and the rubber matrix [17]. The present $T_{g}$ behavior is exactly coincide with the results which obtained from the dynamic properties of RFCs [18]. The activation energy of glass transition can be achieved by using the Kissinger formula, which was initially derived for the crystallization process but it is suggested as being valid for the glass transition $[19,20]$. This formula has the following form:

$$
\ln \left(\frac{\beta}{T_{g}^{2}}\right)=-\frac{E_{g}}{R T_{g}}+\ln \frac{A R}{E_{g}}
$$

where $R$ is the universal gas constant, $\beta$ is heating rate, $T_{g}$ is the glass transition temperature, $E_{g}$ is the glass transition activation energy, and $A$ is the pre-exponential factor. The change of the entropy $\left(\Delta S^{\#}\right)$ may be calculated according to the relation $[21,22]$ :

$$
\Delta S^{\#}=R \ln \left(\frac{A h}{e \chi k_{B} T_{g}}\right)
$$

where $A$ is the pre-exponential factor obtained from the Kissinger method, $e$ is the Neper number, $\chi$ is transition factor, $k_{B}$ is the Boltzmann constant, $h$ is the Plank constant. The change of enthalpy $\left(\Delta H^{*}\right)$ may be obtained according to:

$$
\Delta H^{\#}=E^{\#}-R T_{g}
$$

where $E^{\#}$ is the activation energy. The change of Gibbs free energy $\Delta G^{\#}$ for the glass transition process can be calculated using the well known thermodynamic relation:

$$
\Delta G^{\#}=\Delta H^{\#}-T_{g} \Delta S^{\#}
$$

The variation of glass transition temperature with heating rate $\left(\beta=10,20,30,40^{\circ} \mathrm{C} / \mathrm{min}\right)$ is represented in Figure 4 for NR and 90 phr loading samples (for sake of brevity). The values of $E_{g}$ can be estimated from the plot of $\ln \left(\frac{\beta}{T_{g}^{2}}\right)$ versus $1 / T_{g}$ relation (Figure 5) whose slope is $-E_{g} / R$.
The values of the activation parameters are summarized in Table 3 . The activation energy takes values between $(53-110 \mathrm{~kJ} / \mathrm{mol})$. The higher values of activation energy can be attributed to the adhesion between the ferrite particles and NR matrix [10] as a result of increasing ferrite loading up to $160 \mathrm{phr}$. After this ferrite loading the dilution effect occurs as a result of the diminishing volume fraction of the polymer in the composites. The values of $\Delta S^{\#}$ for glass transition are positive indicating that the corresponding activated composites have higher disorderness than the initial state. The positive values of $\Delta G^{\#}$ indicated that glass transition process is not spontaneous at room temperature. The larger $\Delta G^{\#}$, the harder transition process. The endothermic peaks in DSC curves agree well with the positive sign of the activation enthalpy. The larger values of $\Delta H^{\#}$ means more energy needed for transition.

\subsection{Thermal Decomposition Characteristics and Thermal Stability}

Figure 6 shows the Thermogravimetric (TG) and its derivative DTG curves for natural rubber-barium ferrite composites. The decomposition step as well as percentage weight loss are given in Table 4. TG and DTG curves of all samples have shown the same general shape, suggesting that the decomposition mechanisms are simi-

Table 4. TG and DTG data for natural rubber-barium ferrite composites in the decomposition region.

\begin{tabular}{ccccc}
\hline \multirow{2}{*}{ Barium ferrite loading $(\mathrm{Phr})$} & \multicolumn{3}{c}{ Temperature ${ }^{\circ} \mathrm{C}$} & \multirow{2}{*}{ \% Weight loss } \\
\cline { 2 - 4 } & Start & End & $T_{p}$ & \\
\hline 30 & 324 & 401 & 379 & 52.13 \\
90 & 331 & 399 & 384 & 43.17 \\
140 & 312 & 401 & 380 & 29.97 \\
160 & 314 & 401 & 384 & 26.26 \\
180 & 324 & 401 & 384 & 22.85 \\
200 & 326 & 401 & 382 & 20.7 \\
\hline
\end{tabular}

$T_{p}=$ Peak temperature of the derivative TG. 

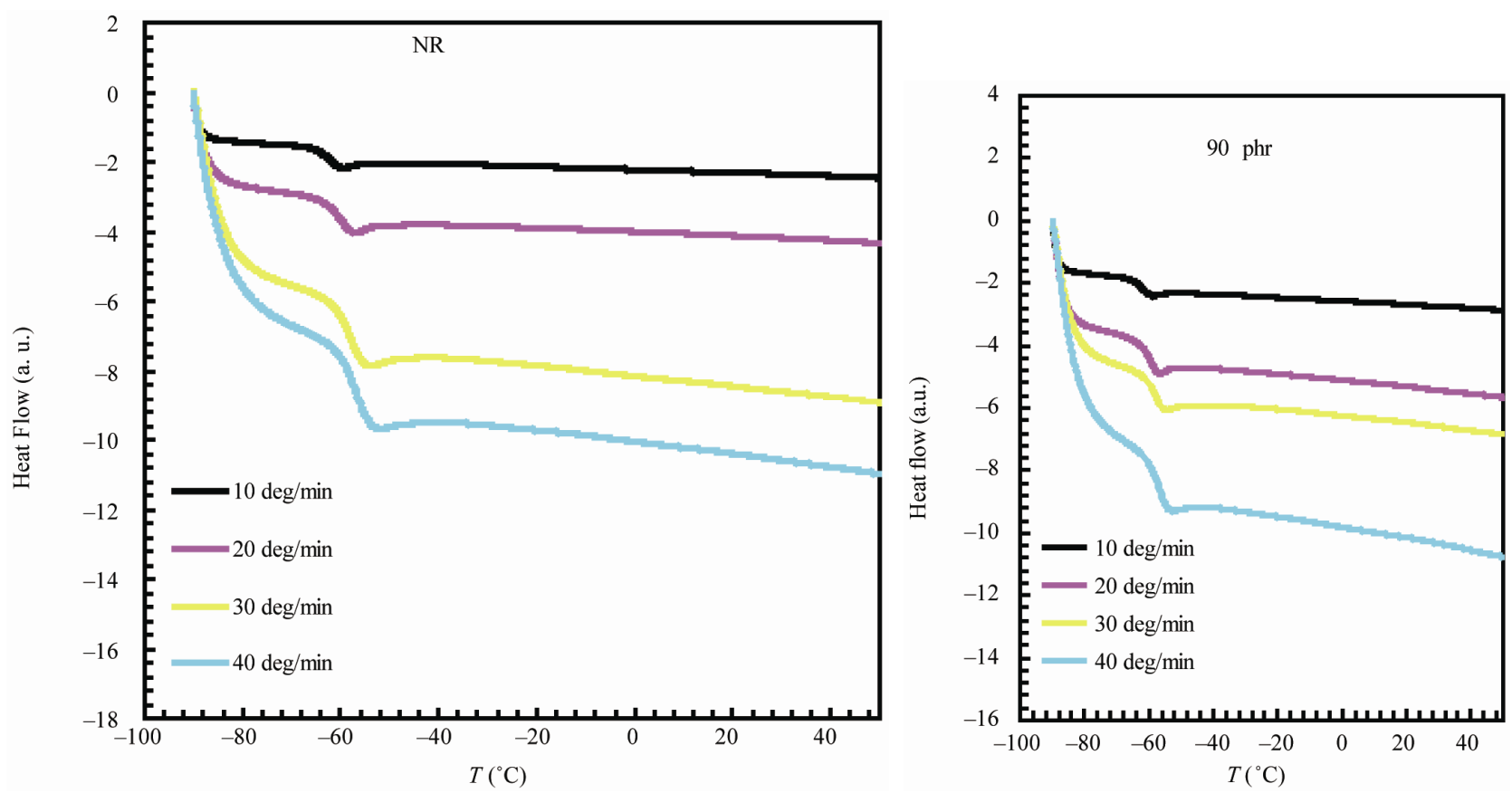

Figure 4. DSC thermograms for natural rubber and 90 phr composite samples at different heating rates.

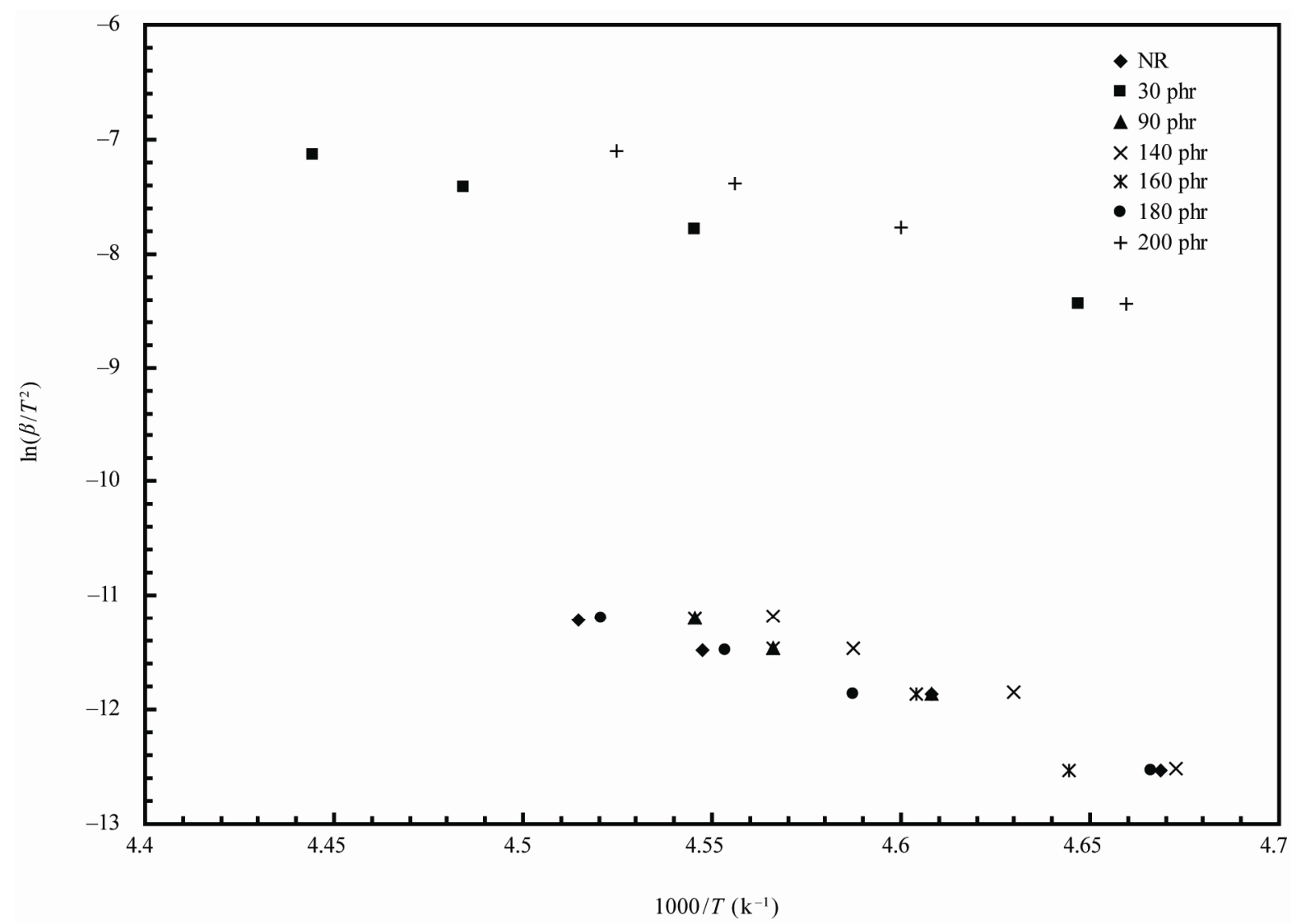

Figure 5. Kissinger plots for natural rubber-barium ferrite composites.

lar. All samples studied exhibited an initial small mass loss attributed to the elimination of volatile components such as water, and ammonia residue [23]. All samples are stable up to $300^{\circ} \mathrm{C}$. It can be seen that the $\mathrm{TG}$ curves 

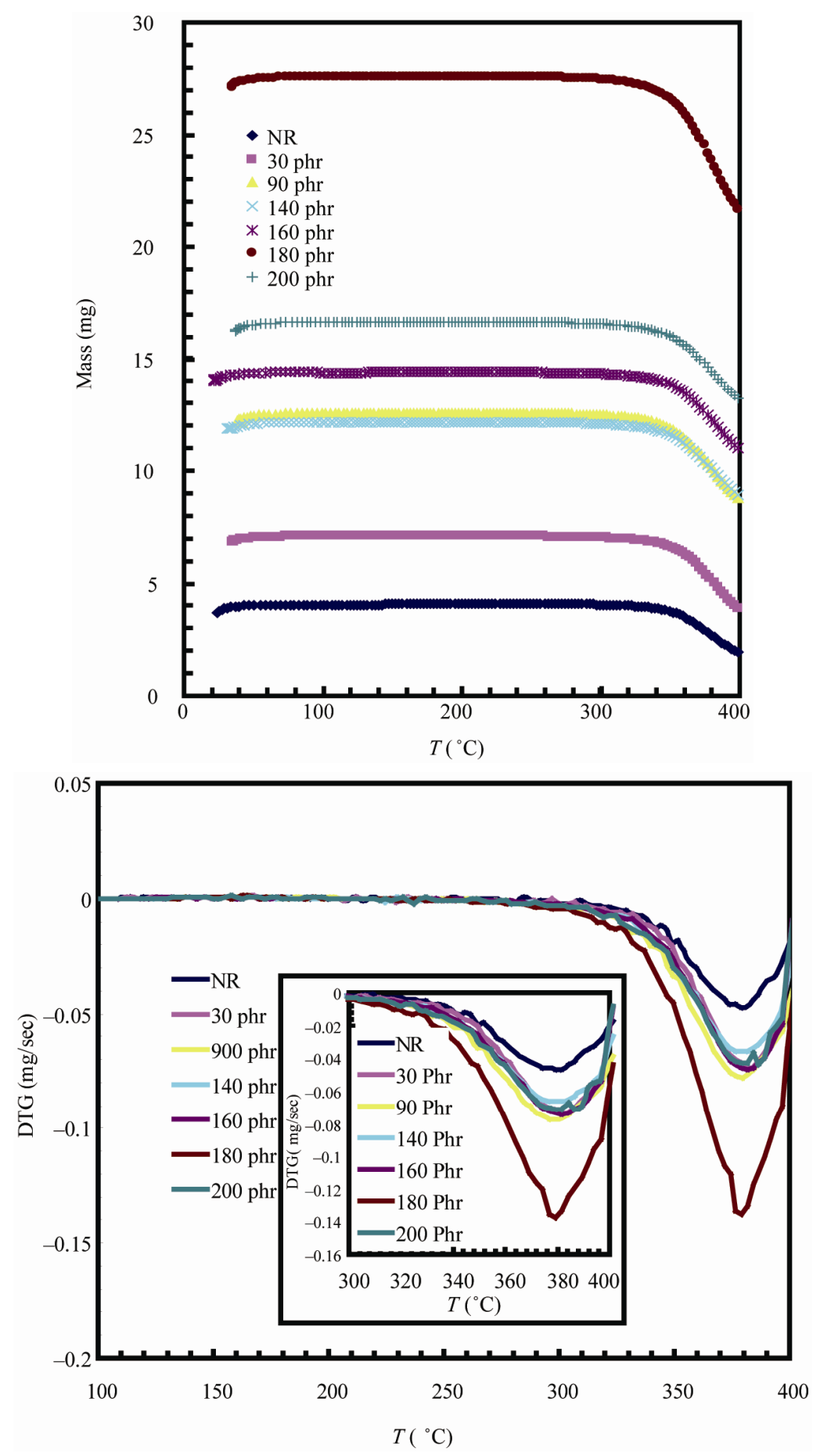

Figure 6. TG and DTG curves for natural rubber-barium ferrite composites.

have only one large plateau and the DTG curves have only one degradation peak, indicating that thermal degradation of samples is mostly one stage process. The decomposition ranged from approximately $300^{\circ} \mathrm{C}-400^{\circ} \mathrm{C}$, with mass loss ranging from $52.17 \%-19.43 \%$, and this is assigned to thermal decomposition of natural rubber into monomers, dimers, trimers, etc.

The temperature of the maximum loss rate or peak temperature of the DTG curves ranges from $379^{\circ} \mathrm{C}$ $387^{\circ} \mathrm{C}$, and the decreasing of weight loss is due to the increase of non-volatile filler content in the composite samples.

\subsection{Kinetics of Thermal Degradation}

It has been reported that above $300^{\circ} \mathrm{C}$, the volatilization 
of natural rubber becomes more rapid and is substantially complete at temperature near $400^{\circ} \mathrm{C}$. In cis-1,4-polyisoprene vulcanizates, the transitions which occur above $300^{\circ} \mathrm{C}$ have been found to be of greater significance because of a strong correlation between the thermal properties and the elastomer combustibility [24]. Therefore, the kinetic parameters have been evaluated only for the major decomposition observed between $300^{\circ} \mathrm{C}$ and $400^{\circ} \mathrm{C}$. The kinetic parameters are calculated using Coates and Redfern method [25]:

$$
\ln \left[\frac{-\ln (1-\alpha)}{T^{2}}\right]=-\frac{E^{\neq}}{R T}+\ln \frac{A R}{\beta E^{\neq}}
$$

where $\alpha$ is fraction of decomposition, $E^{\neq}$is the activation energy and other symbols as defined before. Therefore, plotting $\ln \left[\frac{-\ln (1-\alpha)}{T^{2}}\right]$ against $1 / T$ according to Equation (5) should give a straight line whose slope is directly proportional to the activation energy $\left(-\frac{E^{\ddagger}}{R}\right)$. The activation entropy $\Delta S^{\#}[26]$ :

$$
\Delta S^{\#}=2.303\left(\log \frac{A h}{k_{B} T_{p}}\right) R
$$

The activation enthalpy $\Delta H^{\#}$, and the Gibbs free energy $\Delta G^{\#}$ were calculated using the following Equations (3) and (4) with replacing $T_{g}$ by $T_{p}\left(T_{p}\right.$ is the peak temperature of DTG). The entropy $\Delta S^{\#}$ gives information about the degree of disorder of the system, the enthalpy $\Delta H^{\#}$ gives information about the total thermal motion and Gibbs or free energy $\left(\Delta G^{\#}\right)$ gives information about the stability of the system.

Figure 7 represents the Coats-Redfern plots of the decomposition step for NR and 90 phr loading samples



(for sake of brevity). The calculated kinetic parameters are given in Table 5. The higher values of activation energies show an improved resistance to degradation process.

\section{Conclusion}

Natural rubber-barium ferrite composites have been prepared. Variation of particle sizes, distribution, and the homogeneous dispersion can be observed Via SEM. Also there is no tendency to form agglomerates in the present composite system even at high loading level. Infrared studies indicated the presence of two strong absorption bands $v_{1}$ and $v_{2}$. The change in the band position is due to the change in the $\mathrm{Fe}^{3+}-\mathrm{O}^{2-}$ internuclear distance of the octahedral and tetrahedral sites. There is small variation of the glass transition temperatures under increasing of ferrite loading. The thermodynamic parameters values indicated that the glass transition process is more disorderrness, not spontaneous or harder process, more energy

Table 5. Thermodynamic parameters for natural rubberbarium ferrite composites in the decomposition region.

\begin{tabular}{ccccc}
\hline $\begin{array}{c}\text { Barium ferrite } \\
\text { loading }(\mathrm{phr})\end{array}$ & $\begin{array}{c}E^{\#} \\
(\mathrm{~kJ} / \mathrm{mol})\end{array}$ & $\begin{array}{c}\Delta S^{\#} \\
(\mathrm{~J} / \mathrm{mol} \cdot \mathrm{K})\end{array}$ & $\begin{array}{c}\Delta H^{\#} \\
(\mathrm{~kJ} / \mathrm{mol})\end{array}$ & $\begin{array}{c}\Delta G^{\sharp} \\
(\mathrm{kJ} /(\mathrm{mol})\end{array}$ \\
\hline 0 & 149 & -315 & 146 & 265 \\
30 & 174 & -271 & 171 & 275 \\
90 & 157 & -417 & 154 & 312 \\
140 & 178 & -322 & 175 & 298 \\
160 & 168 & -377 & 165 & 310 \\
180 & 165 & -393 & 162 & 312 \\
200 & 181 & -307 & 178 & 296 \\
\hline
\end{tabular}

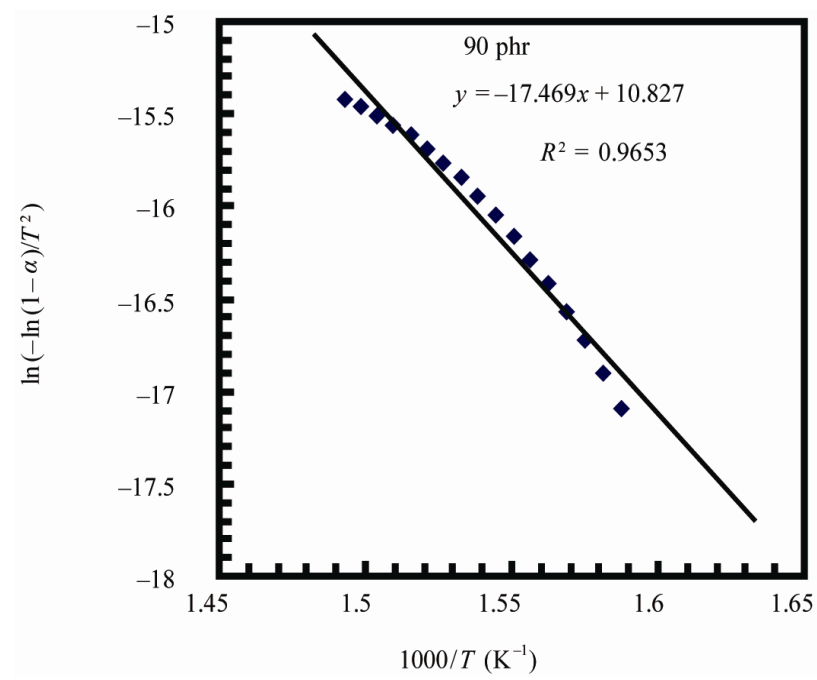

Figure 7. Coats-redfern plots for natural rubber and 90 phr composite samples. 
needed to occur. Increasing of ferrite loading enhance the thermal stability of natural rubber.

\section{REFERENCES}

[1] D. E. El-Nashar, S. H. Mansour and E. Girgis, "Nickel and Iron Nano-Particles in Natural Rubber Composites," Journal of Materials Science, Vol. 41, No. 2, 2006, pp. 5359-5364. doi:10.1007/s10853-006-0179-4

[2] M. H. Makled, T. Matsui, H. Tsuda, H. Mabuchi, M. K. El-Mansy and K. Moric, "Magnetic and Dynamic Mechanical Properties of Barium Ferrite-Natural Rubber Composites," Journal of Material Processing Technology, Vol. 160, No. 2, 2005, pp. 229-233.

doi:10.1016/j.jmatprotec.2004.06.013

[3] E. C. Milke, M. Rei, J. P. de Souze and L. Schaeffer, "Powder Injection Molded Strontium-Ferrite Magnets," International Journal of Powder Metallurgy, Vol. 37, No. 5, 2001, pp. 47-51.

[4] J. U. Otaigbe, H. S. Kim and J. Xiao, "Effect of Coupling Agent and Filler Particle Size on Melt Rheology of Polymer-Bonded Nd-Fe-B Magnets," Polymer Composites, Vol 20, No. 5, 1999, pp. 697-704. doi:10.1002/pc.10393

[5] J. Xiao and J. U. Otaigbe, "Polymer Bonded Magnets. II. Effect of Liquid Crystal Polymer and Surface Modification on Magneto-Mechanical Properties," Polymer Composites, Vol. 21, No. 2, 2000, pp. 332-342. doi:10.1002/pc. 10190

[6] M. A. Solomon, P. Kurian, P. A. Joy and M. R. Anantharaman, "Processability and Magnetic Properties of Rubber Ferrite Composites Containing Barium Ferrite," International Journal of Polymeric Material, Vol. 53, 2004, pp. 565-575.

[7] M. A. Solomon, P. Kurian, M. R. Anantharaman and P. A. Joy, "Evaluation of the Magnetic and Mechanical Properties of Rubber Ferrite Composites Containing Strontium Ferrite," Polymer Plastic Technology and Engineering, Vol. 43, No. 4, 2004, pp. 1013-1028. doi:10.1081/PPT-120038602

[8] D. R. Saini, V. M. Nadkarni, P. D. Grover and K. D. P. Nigam, "Dynamic Mechanical, Electrical and Magnetic Properties of Ferrite Filled Styrene-Isoprene-Styrene," Journal of Material Science, Vol. 21, No. 10, 1986, pp. 3710-3716. doi:10.1007/BF02403026

[9] M. A. Solomon, P. Kurian, M. R. Anantharaman and P. A. Joy, "Cure Characteristics and Dielectric Properties of Magnetic Composites Containing Strontium Ferrit," Journal of Elastomers and Plastics, Vol. 37, No. 2, 2005, pp. 109-121. doi:10.1177/0095244305046488

[10] M. H. Makled, T. Matsui, H. Tsuda, H. Mabuchi, M. K. El-Mansy and K. Morii, "Effect of Particle Size and Its Distribution on the Fabrication and Magnetic Properties of Barium Ferrite Powders Prepared from Coprecipitated Precursors," Journal of the Ceramic Society of Japan, Vol. 112, No. 1304, 2004, pp. 200-203. doi:10.2109/jcersj.112.200

[11] J. Xiao and J. U. Otaigbe, "Polymer-Bonded Magnets: Part I. Analytic Thermogrvimetry to Determine the Effect of Surface Modification on Dispersion of Nd-Fe-B Filler," Journal of Materials Research, Vol. 14, No. 7, 1999, pp. 2893-3896. doi:10.1557/JMR.1999.0386

[12] R. D. Waldrons, "The Infrared Spectra of Ferrites," Physics Review, Vol. 99, No. 6, 1955, pp. 1727-1735. doi:10.1103/PhysRev.99.1727

[13] M. A. Mousa and M. A. Ahmed, "Electrical Conduction in $\gamma$-Irradiated and Unirradiated Zinc-Iron Ferrites," Chemistry and Material Science, Vol. 23, No. 9, 1988, pp. 3083-3087. doi:10.1007/BF00551277

[14] O. S. Josyulu and Sobhanadri, "The Far-Infrared Spectra of Some Mixed Cobalt Zinc and Magnesium Zinc Ferrites," Physica Status Solidi (a), Vol. 65, No. 2, 1981, pp. 479-483. doi:10.1002/pssa.2210650209

[15] J. Preudhomme and P. Tarae, "Infrared Studies of Spinels: III: The Normal II-III Spinels," Spectrochim Acta Part A, Vol. 27, No. 9, 1971, pp. 1817-1835.

[16] D. W. Brazier, "Applications of Thermal Analytical Procedures in the Study of Elastomers and Elastomer Systems," Rubber Chemistry and Technology, Vol. 53, No. 3, 1980, pp. 437-512. doi:10.5254/1.3535051

[17] A. D. Falco, S. Goyanes, G. H. Rubiolo, I. Mondrayon and A. Marzocca, "Carbon Nanotubes as Reinforcement of Styrene-Butadiene Rubber," Applied Surface Science, Vol. 254, No. 1, 2007, pp. 262-265. doi:10.1016/j.apsusc.2007.07.049

[18] M. H. Makled, Y. Washiya, H. Tsuda and T. Matsui, "Effect of Coprecipitated Barium Ferrite on the Cure Characteristics and Dynamic Properties of Natural Rubber-Ferrite Composites around Percolation," Journal of Applied Polymer Science, Vol. 113, No. 5, 2009, pp. 3294-3299. doi:10.1002/app.30263

[19] H. E. Kissinger, "Reaction Kinetics in Differential Thermal Analysis," Analytical Chemistry, Vol. 29, No. 11, 1957, pp. 1702-1706. doi:10.1021/ac60131a045

[20] R. P. Wang, C. J. Zha, A. V. Rode, S. J. Madden and B. Luther-Davies, "Thermal Characterization of Ge-As-Se Glasses by Differential Scanning Calorimetry," Journal of Materials Science: Materials Electronics, Vol. 18, No. 1, 2007, pp. 419-422.

[21] B. Boonchom and S. Puttawong, "Thermodynamics and Kinetics of the Dehydration Reaction of $\mathrm{FePO}_{4} \cdot 2 \mathrm{H}_{2} \mathrm{O}$," Physica B, Vol. 405, No. 9, 2010, pp. 2350-2355. doi:10.1016/j.physb.2010.02.046

[22] L. Vlaev, N. Nedelchev, K. Gyurova and M. Zagorcheva, "A Comparative Study of Non-Isothermal Kinetics of Decomposition of Calcium Oxalate Monohydrate," Journal of Analytical and applied Pyrolysis, Vol. 81, No. 2, 2008, pp. 253-262. doi:10.1016/j.jaap.2007.12.003

[23] L. C. S. de Oliveira, E. J. de Arruda, R. B. da Costa, P. S. Goncalves and A. E. Job, "Evaluation of Thermal Behavior of Latex Membranes from Genetically Improved Rubber Tree (Hevea Brasiliensis)," Thermochimica Acta, Vol. 445, No. 1, 2006, pp. 27-31. doi:10.1016/j.tca.2006.03.027

[24] L. Slusarski and G. Janowska, "The Effect of the Network Structure of the Thermal Properties of Cis-1,4-Polyisoprene Vulcanizates," Journal of Thermal Analytical and 
Calorimetry, Vol. 29, No. 1, 1984, pp. 95-104. doi:10.1007/BF02069944

[25] A. W. Coats and J. P. Redfern, "Kinetic Parameters from Thermogravimetric Data," Nature, Vol. 201, No. 4914, 1964, pp. 68-69. doi:10.1038/201068a0
[26] F. Yakuphanoglu, A. O. Gorgulu and A. Cukurovali, “An Organic Semiconductor and Conduction Mechanism: N-[5-methyl-1,3,4-tiyodiazole-2-yl] Ditiyocarbamate Compound," Physica B, Vol. 353, No. 3-4, 2004, pp. 223-229. doi:10.1016/j.physb.2004.09.099 